\title{
Desempenho comparativo em tanques-rede de três linhagens da tilápia do Nilo - Oreochromis niloticus: comum, chitralada e mestiço
}

\author{
Ida Vanderlei Tenório ${ }^{1 *}$ \\ Maria do Carmo Figueredo Soares ${ }^{2}$ \\ José Patrocínio Lopes ${ }^{3}$ \\ ${ }^{1}$ Universidade Estadual de Alagoas, Avenida Manuelito Bezerra Lima, 851 \\ CEP 57400-000, Pão de Açúcar - AL, Brasil \\ ${ }^{2}$ Departamento de Pesca, Universidade Federal Rural de Pernambuco, Brasil \\ ${ }^{3}$ Companhia Hidro Elétrica do São Francisco, Brasil \\ *Autor para correspondência \\ ida_tenorio@hotmail.com
}

Submetido em 14/06/2011

Aceito para publicação em 18/11/2011

\section{Resumo}

O objetivo deste experimento foi comparar o desempenho de três linhagens de tilápia do Nilo em tanquesrede: linhagem chitralada (T1), linhagem comum (T2), mestiço (T3), com três repetições, durante 98 dias. Os peixes foram estocados em nove tanques-rede com volume útil de $1 \mathrm{~m}^{3}$ cada, contendo 200 peixes $/ \mathrm{m}^{3}$, em um viveiro de $2.500 \mathrm{~m}^{2}$ e $1,6 \mathrm{~m}$ de profundidade média. As tilápias foram alimentadas com ração contendo $32 \%$ de proteína bruta e o tamanho do "pellet" foi de 4 a $6 \mathrm{~mm}$. Foram realizadas mensurações com amostra de 20 peixes/tanque. Semanalmente foram monitoradas variáveis da água: temperatura, $\mathrm{pH}$, oxigênio dissolvido e condutividade elétrica, às $5 \mathrm{~h}$ da manhã. Foram comparados: ganho em peso, conversão alimentar, biomassa produzida, taxa de crescimento específico e sobrevivência. O mestiço não apresentou diferença significativa quando comparado à linhagem chitralada, porém quando estas duas linhagens foram comparadas à linhagem comum, houve diferença significativa para ganho em peso $(342,02 \mathrm{~g} ; 332,25 \mathrm{~g} ; 231,5 \mathrm{~g})$ biomassa produzida $\left(66,27 ; 69,16 ; 43,51 \mathrm{~kg} / \mathrm{m}^{3}\right)$ e crescimento específico $(1,83 ; 2,02 ; 1,59)$. A conversão alimentar não diferiu significativamente entre os tratamentos $(1,66 ; 1,68 ; 1,47)$. Para sobrevivência o mestiço não diferiu entre as duas outras linhagens, contudo a linhagem chitralada diferiu significativamente da linhagem comum $(97,67 \%$, 94,00\%). Conclui-se que a linhagem Chitralada como também o mestiço são adequadas ao sistema de criação em tanques-rede.

Palavras-chave: Desempenho Zootécnico, Linhagens de tilápia, Oreochromis niloticus, Tanques-rede

\section{Abstract}

Comparative growth in cages of three strains of Nile tilapia (Oreochromis niloticus): common, chitralada and mixed race. The purpose of this experiment was to compare the performance of three strains of Nile tilapia, chitralada (T1), a common lineage (T2) and a mixed race (T3), in cages over a period of 98 days. The fish were stocked in nine cages with a volume of $1 \mathrm{~m}^{3}$ each, where there were $200 \mathrm{fish} / \mathrm{m}^{3}$, in a pond that was 
$2,500 \mathrm{~m}^{2}$ and $1.6 \mathrm{~m}$ deep. The study had three replications, and the tilapia were fed a diet containing $32 \%$ crude protein with pellets that were 4-6mm. Measurements were made by sampling $20 \mathrm{fish} / \mathrm{tank}$. Variables in water temperature, $\mathrm{pH}$, dissolved oxygen and electrical conductivity were monitored weekly at $5 \mathrm{am}$. We compared weight gain, feed conversion, biomass, specific growth rate and survival. The mixed race was not significantly different when compared to chitralada lineage, but when these two strains were compared to the common lineage, there was a significant difference for weight gain, specific growth and biomass. The feed conversion did not differ significantly between treatments $(1.66 ; 1.68 ; 1.47)$. The survival of the mixed race did not differ when compared to the other strains; however, the chitralada lineage differed significantly from the common strain $(97.67 \% ; 94.00 \%)$. The results indicate that the mixed race adapted to the culture system evaluated.

Key words: Growth rate, Oreocromis niloticus, Survival, Tilapia strain, Weight gain

\section{Introdução}

No século passado, a tilápia foi introduzida em quase todo mundo, sendo atualmente criada comercialmente em quase 100 países e, neste século, deverá ser a espécie mais importante para a piscicultura comercial (FITZSIMMONS, 2000).

As primeiras importações deste peixe no Brasil ocorreram no ano de 1953, em São Paulo e, no Nordeste em 1956, através do Departamento Nacional de Obras Contra as Secas (DNOCS), sendo introduzida em ambos os casos a Tilapia rendalli.

Em 1971, visando à produção de híbridos e de alevinos para o povoamento dos reservatórios públicos da região Nordeste e para o fomento à criação, mais duas espécies, Oreochromis niloticus e Oreochromis hornorum, provindas de Bouaké, Costa do Marfim, no oeste Africano, foram trazidas para a Estação de Piscicultura do Departamento Nacional de Obras Contra as Secas - DNOCS em Pentecostes, Ceará, pois apresentavam um grande potencial para a piscicultura nordestina (GALLI; TORLONI, 1987; KUBITZA, 2003, KUBITZA, 2011).

A tilápia chegou ao Brasil com um reduzido número de exemplares, 20 reprodutores da Tilápia do Nilo e 20 reprodutores de Zanzibar (BARD et al., 1974), e com o passar dos anos os seus descendentes foram distribuídos por todo Brasil ocorrendo retrocruzamento, o que acarretou altos índices de anomalias genéticas, resultando em uma diminuição do crescimento e rendimento de carcaça (ZIMMERMANN, 2000a; SUGANUMA et al., 2003).
No início da década de 1990, com a difusão da tecnologia de reversão sexual, a produção de tilápia do Nilo começou a ser incrementada. Os estoques comerciais e institucionais existentes não correspondiam às necessidades de produção, pois havia ocorrido uma perda da pureza genética da espécie devido à hibridação intraespecífica, resultando em altos níveis de consanguinidade, com redução da variabilidade genética, ocorrendo perda da resistência e diminuição da capacidade de adaptação a novos ambientes (SUGANUMA et al., 2003).

Muitos dos estoques de reprodutores comerciais têm sido propositalmente ou acidentalmente, hibridizados. Em muitos casos isto é benéfico, pois surge o vigor do híbrido. Por outro lado quando os estoques ainda estão relativamente puros, perde-se o benefício da heterose (FITZSIMMONS, 2000).

De acordo com Zimmermann (2000a), a situação de consanguinidade em todo o país e, principalmente no oeste do Paraná, atingiu níveis alarmantes, cerca de $35 \%$ da maioria das reproduções. Isto ocasionou baixa produtividade dos alevinos produzidos, havendo necessidade de introdução de novos estoques.

Em 1994, foram localizados, em Israel, Flórida, Filipinas e Tailândia, estoques de tilápia do Nilo que apresentavam desempenho superior aos estoques brasileiros. Em 1996, foram introduzidos 20.800 reprodutores oriundos de 1.000 diferentes eventos reprodutivos de 20 famílias de tilápia do Nilo linhagem chitralada ou Thai-chitralada, sendo selecionada nesta população características como ganho em peso, conformação corporal e docilidade (KUBITZA, 2003). Teixeira (2006) afirma que a Bahia pesca S. A., importou 
30.000 alevinos de reprodutores da variedade Chitralada da Estação Experimental do "Asian Institute of Techinology" - AIT, no ano 2000, sendo uma parte deste plantel doada a Estação de Piscicultura da Companhia Hidro Elétrica do São Francisco (CHESF).

Em 2002, uma nova linhagem de tilápia do Nilo denominada "GenoMar Supreme Tilapia" - GST foi trazida para o Brasil através da Piscicultura Aquabel, e em 2005 foi a vez da Linhagem "Genetically Improved Farmed Tilapia" - GIFT, ambas oriundas da Malásia (ZIMMERMANN, 2003). Ainda segundo o mesmo autor a origem das duas linhagens é a mesma, sendo que a partir de 1999, o desenvolvimento dessas linhagens ocorreu de forma independente.

Quando comparadas a linhagem Chitralada e a outras populações de nilóticas, estas linhagens introduzidas mais recentemente apresentam ganho de peso superior em 30 a $80 \%$ dependendo das condições ambientais (ZIMMERMANN, 2003), porém a tilápia do Nilo, linhagem chitralada, vem sendo a linhagem mais cultivada e tem sido bem aceita pelos produtores brasileiros principalmente os nordestinos, por apresentarem características tais como, precocidade em ganho de peso, alta conversão alimentar e docilidade. Além de apresentar um altíssimo potencial genético segundo Carvalho-Filho (2000),

A linhagem chitralada apresenta excelente resultado zootécnico, mas é muito suscetível ao manuseio, ocorrendo em muitas criações uma elevada taxa de mortalidade, pois o sistema de criação utilizado para produzir tilápia requer um elevado manejo para um controle final da produção, utilizando-se o sistema de fases.

Este sistema otimiza o uso das unidades de produção tanto em viveiros, como em tanques-rede e "raceway", possibilitando a obtenção de maiores índices de produtividade e melhorando a previsão dos números de produção. No entanto, a adoção desta estratégia exige um uso mais intenso de mão-de-obra e um sistema eficiente de movimentação dos peixes, (KUBITZA, 2000).

A tilápia do Nilo, linhagem comum, vem apresentando nos últimos anos índices de crescimento baixo, quando comparados a outras linhagens introduzidas no Brasil, entretanto apresenta uma maior rusticidade, consequentemente menores taxas de mortalidade. Esperando encontrar o ponto de equilíbrio entre os altos índices alcançados pela linhagem chitralada, e a adaptação e rusticidade características da linhagem comum, foi feito um cruzamento entre as duas linhagens. Este cruzamento resultou em uma terceira linhagem que, neste experimento foi denominada mestiço.

O objetivo deste trabalho foi comparar três linhagens da tilápia do Nilo: linhagem chitralada, linhagem comum e o mestiço, a fim de observar qual linhagem se adequa melhor às condições de cultivo local, sendo avaliadas através do ganho em peso, conversão alimentar, sobrevivência, biomassa produzida e taxa de crescimento específico.

\section{Material e Métodos}

O experimento foi realizado na Fazenda Pau Ferro no município de Pão de Açúcar, em Alagoas, e teve duração de 98 dias.

Foram utilizados 1.800 juvenis revertidos de tilápia do Nilo sendo 600 da linhagem chitralada (T1), 600 da linhagem comum (T2), e 600 mestiços (T3) resultante do cruzamento entre a tilápia do Nilo linhagem chitralada e a tilápia do Nilo Linhagem Comum, todos os alevinos para o experimento foram cedidos pela Estação de Produção de alevinos da Companhia Hidro Elétrica do São Francisco - CHESF, em Paulo Afonso - BA, as matrizes da tilápia do Nilo comum foram oriundas da Estação de Piscicultura Pedro de Azevedo em Icó-Ceará pertencente ao DNOCS e as matrizes da linhagem Chitralada vindas da Bahia Pesca S. A., e foram distribuídos utilizando-se o delineamento inteiramente casualizado com três repetições cada.

Os peixes foram alojados em nove tanques-rede em tela alumínio (malha de $25 \mathrm{~mm}$ ) medindo $1 \mathrm{mx} 1 \mathrm{mx} 1$, com um volume útil de $1 \mathrm{~m}^{3}$, com uma densidade de 200 peixes $/ \mathrm{m}^{3}$. Os tanques-rede eram providos de anel de alimentação de tela plástica com malha de $2 \mathrm{~mm}$ e, como flutuadores, tubos de PVC de $100 \mathrm{~mm}$. Os tanques-rede foram colocados dentro de um viveiro de $2.500 \mathrm{~m}^{2} \mathrm{e} 1,6 \mathrm{~m}$ de profundidade 
Como foi observado a homogeneidade do lote no momento da estocagem dos tanques-rede foi definido um percentual de $10 \%$ para biometria inicial, mantendo este percentual até o final do experimento, sendo pesados (em gramas) e medidos (em cm). Quando da estocagem apresentavam comprimento e peso médio de $13,25 \mathrm{~cm}$ e $49,17 \mathrm{~g}$ para a linhagem chitralada, $13,96 \mathrm{~cm}$ e $60,00 \mathrm{~g}$ para a linhagem comum e $14,95 \mathrm{~cm}$ e $67,98 \mathrm{~g}$ para o mestiço.

Os peixes foram alimentados com uma ração comercial extrusada com $32 \%$ de proteína bruta e diâmetro do "pellet" de $4 \mathrm{~mm}$, ofertada três vezes ao dia (9h, 12h e $15 \mathrm{~h}$ ), até a saciedade aparente. A partir da primeira mensuração biológica, quando os peixes atingiram peso médio acima de $100 \mathrm{~g}$ foi ofertada uma ração com diâmetro do "pellet" igual a $6 \mathrm{~mm}$, contendo a mesma composição total da ração anterior (Tabela 1).

TABELA 1: Composição bromatológica da ração extrusada ofertada aos juvenis de tilápia do Nilo nos tanques-rede.

\begin{tabular}{lclc}
\multicolumn{1}{c}{ Nutrientes } & Quantidade & Nutrientes & Quantidade \\
\hline $\begin{array}{l}\text { Proteína Bruta } \\
\text { (Mínimo) }\end{array}$ & $32 \%$ & Ferro (mg) & 80 \\
$\begin{array}{l}\text { Extrato etéreo } \\
\text { (Mínimo) }\end{array}$ & $4,0 \%$ & Cobre (mg) & 10 \\
$\begin{array}{l}\text { Matéria fibrosa } \\
\text { (Máximo) }\end{array}$ & $7,0 \%$ & Zinco (mg) & 100 \\
$\begin{array}{l}\text { Matéria mineral } \\
\text { (Máximo) }\end{array}$ & $14,0 \%$ & Manganês (mg) & 50 \\
$\begin{array}{l}\text { Cálcio (Máximo) } \\
\text { Fósforo (Mínimo) }\end{array}$ & $2,5 \%$ & Iodo (mg) & 1,0 \\
\hline
\end{tabular}

Fornecida pelo fabricante. Composição do produto: carbonato de cálcio, farelo de glúten de milho-60, farelo de soja, farelo de trigo, fosfato bicalcico, óleo de peixe refinado, milho integral moído, cloreto de sódio, premix mineral vitamínico, farinha de peixe.

Durante o período experimental foram realizadas quatro mensurações biológicas no período de 30 de janeiro a 9 de maio, com amostragem de $10 \%$ dos indivíduos de cada unidade experimental, sempre realizadas pela manhã, registrando-se o comprimento total com o auxílio do ictiômetro e o peso individual em balança com precisão de $1 \mathrm{~g}$.

Após este procedimento os peixes eram colocados em um outro balde com uma solução a 6ppm de cloreto de sódio, conforme recomendação de Gomes et al.
(2002), como um tratamento preventivo e profilático contra fungos. Não houve mortalidade durante e após as mensurações biológicas.

A partir dos valores obtidos de peso dos peixes e do consumo de ração foram calculados os seguintes parâmetros de desempenho: Ganho em peso (GP), conversão alimentar aparente (CAA), biomassa produzida (BP), taxa de sobrevivência (TS), considerando-se a mortalidade constante durante o período de criação e taxa de crescimento específico.

Semanalmente foi efetuado o monitoramento de algumas variáveis físicas e químicas da água dentro do tanque-rede e fora, no ambiente do viveiro. As medições foram feitas às 5 horas da manhã, quando o oxigênio dissolvido apresentava valores mais baixos, sendo medido a temperatura, oxigênio dissolvido, $\mathrm{pH}$ e condutividade elétrica no ambiente do viveiro e dentro dos tanques-rede, no fundo dos mesmos.

Próximo ao término do experimento, em função do baixo teor de oxigênio dissolvido, que chegou a atingir $0,53 \mathrm{mg} / \mathrm{L}$, foi colocado no viveiro um aerador, de $2 \mathrm{cv}$, com capacidade de transferência de oxigênio de $3,0 \mathrm{~kg} . \mathrm{O} /$ $\mathrm{cvh}$, que funcionou das $21 \mathrm{~h}$ às $6 \mathrm{~h}$ diariamente e até $\mathrm{o}$ final do experimento.

Para a análise estatística dos dados, considerouse o delineamento inteiramente casualizado (DIC), com desenho experimental $3 \times 3$, (três linhagens e três repetições), efetuando-se a análise de variância (ANOVA) complementada pelo teste de agrupamento das médias (teste de Tukey) ao nível de 5\% de probabilidade, para comparar os efeitos dos tratamentos sobre o ganho em peso, conversão alimentar aparente, taxa de crescimento específico e sobrevivência (MENDES, 1999).

\section{Resultados e Discussão}

A temperatura da água se mostrou bastante homogênea tanto nos tanques-rede como no seu entorno mantendo-se entre $25^{\circ} \mathrm{C}$ e $27,4^{\circ} \mathrm{C}$ durante o experimento.

Os valores do oxigênio dissolvido, no período de criação, dentro dos tanques-rede e fora, no ambiente do viveiro, apresentaram um mínimo de $0,53 \mathrm{mg} / \mathrm{L}$ e um máximo de $6,33 \mathrm{mg} / \mathrm{L}$, sempre às 5 horas da manhã. 
No início do experimento, o valor médio encontrado foi de $3,33 \mathrm{mg} / \mathrm{L}$ e, ao longo do experimento, quando a biomassa foi aumentando, estes valores foram diminuindo até chegar a valores abaixo de $1 \mathrm{mg} /$ litro. $\mathrm{Na}$ oitava semana houve uma drástica redução da média $(1,07 \mathrm{mg} /$ litro), exigindo assim o uso de um aerador que foi feito a partir da décima semana.

Durante o período de criação o $\mathrm{pH}$ variou de 6,9 a 7,8 no viveiro e de 6,8 a 7,8 dentro dos tanques-rede. Segundo Kubitza (2000), o pH da água de cultivo para a Tilápia do Nilo deve ser mantido entre 6 a 8,5. Portanto os valores obtidos neste experimento estão dentro dos valores de conforto para a espécie.

A condutividade elétrica, que é expressa em $\mu \mathrm{S} / \mathrm{cm}$ e fornece importantes informações sobre o ecossistema: valores altos indicam elevado grau de decomposição, valores baixos elevada produção primária (TAVARES, 1994). Ao longo do período da criação a condutividade elétrica no viveiro e dentro dos tanques-rede aumentou gradativamente, indicando um aumento da matéria orgânica, seja pela sobra de ração ou pelos dejetos produzidos pelos peixes.

As variáveis físicas e químicas da água do viveiro onde se realizou o experimento não tiveram influência nos resultados observados neste trabalho, pois estavam dentro dos níveis de conforto da espécie estudada, com exceção do oxigênio dissolvido que durante o experimento apresentou níveis abaixo do tolerado pela espécie, indicando a necessidade da instalação de um aerador, aumentando a disponibilidade de oxigênio dissolvido e melhorando o desempenho da espécie.

As três linhagens mostraram resultados com uma tendênca positiva e crescente de incremento para o crescimento em peso e comprimento, como mostram as Figuras 1 e 2. Entretanto, a tilápia do Nilo linhagem comum, apresentou crescimento mais baixo ao final do experimento $(291,67 \mathrm{~g}$ e $24,33 \mathrm{~cm})$ quando comparada a tilápia do Nilo, linhagem chitralada $(381,67 \mathrm{~g}$ e $27,86 \mathrm{~cm})$ e, ao mestiço $(410,00 \mathrm{~g}$ e $27,36 \mathrm{~cm})$.

Os exemplares das linhagens chitralada e mestiço apresentaram ganho em peso superior aquelas da linhagem comum $(\mathrm{P}<0,05)$, conforme Tabela 2 . No entanto não diferiram significativamente entre elas.
FIGURA 1: Crescimento em peso dos exemplares de três linhagens de tilápia do Nilo durante 98 dias.

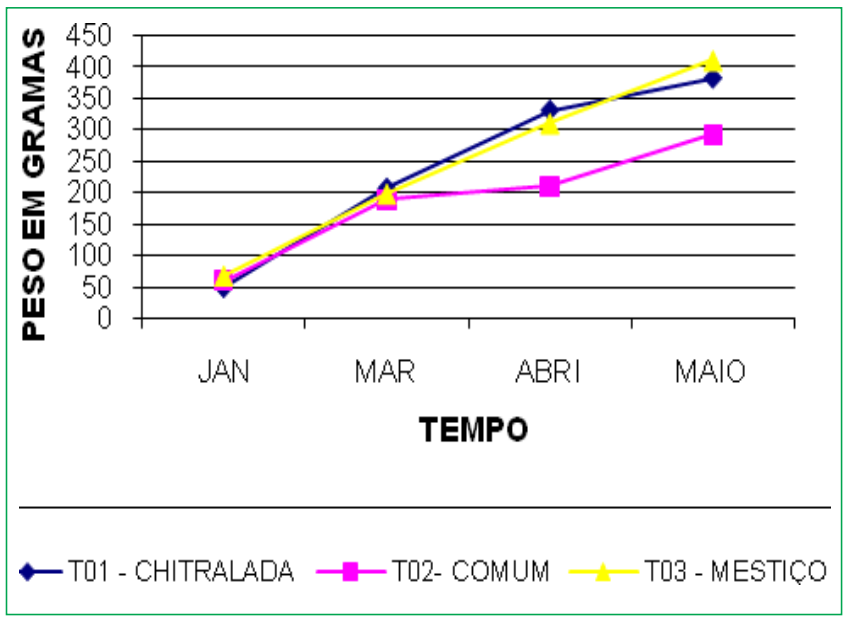

Ao longo do experimento os peixes se apresentaram com desenvolvimento homogêneo, como mostra o Coeficiente de variação, não havendo necessidade de aumentar o percentual de peixes para a amostragem

Diferente dos resultados obtidos neste experimento, Leonhardt et al. (2002), comparando a tilápia do Nilo linhagem chitralada com a linhagem comum e a um mestiço resultante do cruzamento entre as linhagens em tanques-rede de $3 \mathrm{~m}^{3}$ em Londrina - $\mathrm{PR}$, não encontraram diferença significativa no peso final, entre a linhagem comum $(269 \mathrm{~g})$ e a chitralada $(276 \mathrm{~g})$. No entanto, para o mestiço, a diferença foi significativamente inferior $(183 \mathrm{~g})$.

FIGURA 2: Crescimento em comprimento dos exemplares de três linhagens de tilápia do Nilo durante 98 dias.

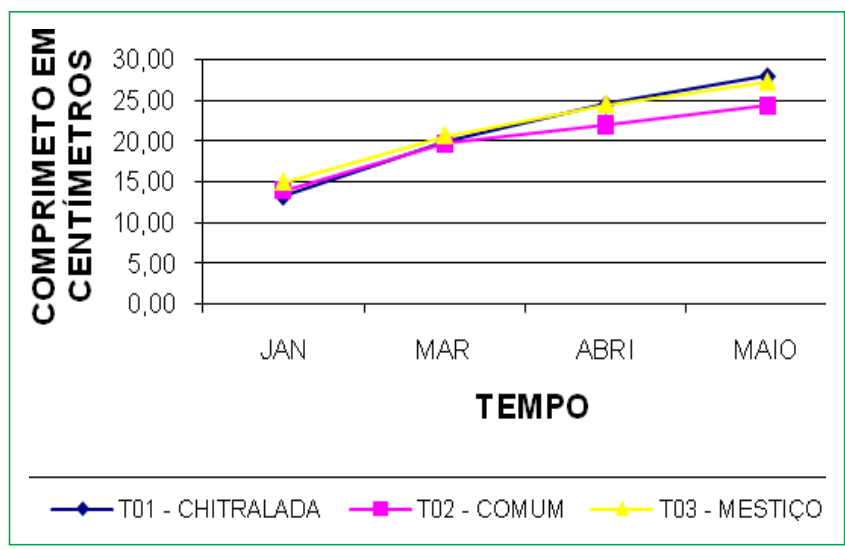


TABELA 2: Principais índices zootécnicos das três linhagens de tilápia do Nilo

\begin{tabular}{|c|c|c|c|c|}
\hline \multirow{2}{*}{ Características } & \multicolumn{3}{|c|}{ Linhagens } & \multirow[b]{2}{*}{$\mathrm{CV} \%$} \\
\hline & Chitralada & Comum & Mestiço & \\
\hline $\begin{array}{l}\text { Duração do } \\
\text { experimento (d) }\end{array}$ & 98 & 98 & 98 & \\
\hline $\begin{array}{l}\text { Número inicial de } \\
\text { peixes }\end{array}$ & 200 & 200 & 200 & \\
\hline $\begin{array}{l}\text { Número final de } \\
\text { peixes }\end{array}$ & 195 & 188 & 193 & \\
\hline Peso inicial (g) & 49,17 & 60,00 & 67,98 & \\
\hline Peso final (g) & 381,67 & 291,67 & 410,00 & \\
\hline Ganho em peso (g) & $332,5^{\mathrm{a}}$ & $231,5^{\mathrm{b}}$ & $342,02^{\mathrm{a}}$ & 8,79 \\
\hline $\begin{array}{l}\text { Comprimento inicial } \\
\text { (cm) }\end{array}$ & 13,25 & 13,96 & 14,95 & \\
\hline $\begin{array}{l}\text { Comprimento final } \\
(\mathrm{cm})\end{array}$ & 30,30 & 25,60 & 28,40 & \\
\hline $\begin{array}{l}\text { Conversão alimentar } \\
\text { aparente }\end{array}$ & $1,66^{\mathrm{a}}$ & $1,68^{\mathrm{a}}$ & $1,47^{\mathrm{a}}$ & 6,23 \\
\hline Sobrevivência & $97,67^{\mathrm{a}}$ & $94,00^{\mathrm{b}}$ & $96,38^{\mathrm{ab}}$ & \\
\hline $\begin{array}{l}\text { Biomassa produzida } \\
\left(\mathrm{kg} / \mathrm{m}^{3}\right)\end{array}$ & $64,96^{\mathrm{a}}$ & $43,51^{\mathrm{b}}$ & $66,27^{\mathrm{a}}$ & 7,67 \\
\hline $\begin{array}{l}\text { Taxa de crescimento } \\
\text { específico }\end{array}$ & $2,08^{\mathrm{a}}$ & $1,59^{\mathrm{b}}$ & $1,83^{\mathrm{a}}$ & 5,45 \\
\hline
\end{tabular}

Letras diferentes na mesma linha diferem estatisticamente no teste de Tukey $(\mathrm{P}<0,05)$.

Massago (2007), em um experimento de 112 dias, e comparando quatro linhagens de Tilápia do Nilo encontrou maior peso final para a linhagem Supreme $(133,2 \mathrm{~g})$, seguido pela GIFT $(121,46 \mathrm{~g})$, chitralada $(112,89 \mathrm{~g})$ e Bouaké (comum) 98,83, resultado semelhante ao encontrado neste trabalho, onde a chitralada, uma linhagem melhorada, e o mestiço, tiveram o melhor desempenho que a tilápia comum (Bouaké). As linhagens melhoradas Chitralada e GIFT apresentaram um peso médio superior em 14,2\% e $22,9 \%$ maior em relação à linhagem Bouaké (comum), demonstrando a supremacia das linhagens melhoradas introduzidas no Brasil.

França et al. (2003), comparando o crescimento de três linhagens de tilápia: a vermelha, a chitralada e a nilótica (comum), em tanques-rede, encontraram diferença significativa entre as três linhagens, tendo a nilótica apresentado o melhor ganho de peso $(549,43 \mathrm{~g})$, seguida pela chitralada $(440,61 \mathrm{~g})$ e por último a vermelha
$(342,00 \mathrm{~g})$ concluindo que as linhagens chitralada e a nilótica (comum) são adequadas à criação intensiva. Estes dados diferem dos resultados obtidos neste trabalho, em que a tilápia do Nilo, linhagem comum, teve o pior desempenho.

Os resultados da tilápia do Nilo Comum dependem da sua origem, do grau de consanguinidade em que se encontram os reprodutores, como também de fatores ambientais (qualidade de água) e do manejo (qualidade e quantidade de ração), que podem levar a ter resultados diferentes nas diversas regiões onde é utilizada.

Resultados similares foram encontrados por Correia et al. (2003), que compararam três linhagens no sistema de criação semi-intensivo em viveiros na Base de Piscicultuta da UFRPE, durante 112 dias e encontraram diferença significativa para as três linhagens, tendo a linhagem chitralada o melhor ganho de peso $(396,40 \mathrm{~g})$, seguido pela vermelha $(225,50 \mathrm{~g})$ e a nilótica o mais baixo desempenho com $(147,00 \mathrm{~g})$. Da mesma forma Boscolo et al. (1999), Rivelli (2001) e Zimmermann (2000b), afirmaram que a tilápia do Nilo, linhagem chitralada, tem um ganho de peso até $50 \%$ superior a outras linhagens.

Neste experimento, o índice de conversão alimentar para cada linhagem foi de 1,66 para chitralada, 1,68 para a linhagem comum e 1,47 para o mestiço, não havendo diferença significativa entre os tratamentos como mostra a Tabela 1. Por outro lado, Mainardes-Pinto et al. (2002), encontraram índices de conversão alimentar para a tilápia do Nilo, linhagem chitralada, cultivada em tanques-rede de pequeno volume, de 1,2; 1,3 e 1,4, mais baixos que os encontrados neste experimento, apesar da mesma densidade de estocagem. Barbosa et al. (2000), avaliando densidades de estocagem em tanques-rede para a tilápia do Nilo, linhagem comum, encontraram índices de conversão alimentar variando entre 1,79, 1,79 e 2,12, maiores, portanto, que o encontrado neste trabalho para a tilápia do Nilo linhagem comum.

A forma e o tipo de apresentação do "pellet" da ração influem na conversão alimentar e no desempenho dos peixes, rações extrusadas (flutuantes) permitem alcançar valores de conversão alimentar próximo à unidade, o que é desejável. Além disso, facilitam o manejo, pois 
permitem uma melhor observação da resposta alimentar dos peixes e minimizam a deterioração da qualidade da água, o que possibilita maior produtividade. Qualidade da ração (composição e palatabilidade) afeta diretamente a conversão alimentar, pois tem grande influência na assimilação dos nutrientes pelas espécies e na qualidade da água no final da criação.

Carmo (2003) encontrou taxas de crescimento específico de 2,42 para a chitralada, 1,77 para a nilótica e 2,06 para a tilápia vermelha, quando comparou três linhagens em sistema de cultivo semi-intensivo em viveiros. O resultado encontrado pelos autores citados difere nos valores dos encontrados no presente trabalho como mostra a Tabela 2, porém concordam que a chitralada e o mestiço tiveram em ambos trabalhos uma melhor taxa de crescimento específico, demonstrando um melhor desempenho das linhagens melhoradas em relação a linhagem comum.

França et al. (2003), trabalhando com três linhagens de tilápia com uma densidade de 120 peixes $/ \mathrm{m}^{3}$, durante 96 dias, obtiveram para a linhagem comum, uma biomassa de $53,74 \mathrm{~kg} / \mathrm{m}^{3} ; 54,32 \mathrm{~kg} / \mathrm{m}^{3}$ para a linhagem chitralada e $46,34 \mathrm{~kg} / \mathrm{m}^{3}$ para a tilápia vermelha não diferindo significativamente entre os tratamentos para a tilápia do Nilo linhagem chitralada e linhagem comum. Os dados de biomassa obtidos neste trabalho (Tabela 1) são superiores para a chitralada e existe uma diferença significativa da linhagem chitralada e do mestiço em relação à linhagem comum.

O desempenho pode variar devido a densidades diferentes, manejo alimentar e qualidade de água, valor nutricional da ração utilizada, mas os resultados estão dentro dos resultados esperados por Lovshin (1997), para a linhagem chitralada e para o mestiço, mas não para a linhagem comum, cuja biomassa produzida por $\mathrm{m}^{3}$ foi menor que $50 \mathrm{~kg}$.

O mestiço não diferiu significativamente, em termos de sobrevivência das outras linhagens. A linhagem comum apresentou diferença significativa entre a linhagem chitralada como pode ser visto na Tabela 1

No período em que foram observados os menores teores de oxigênio dissolvido foi quando ocorreu a maior mortalidade. A partir da décima semana do experimento foi colocado o aerador não havendo mais mortalidade até o final do experimento.

Fülber et al. (2009) encontraram sobrevivência para linhagem GIFT (100\%), seguida pela chitralada (97\%) e Bouaké (comum) (89\%), não apresentando diferença significativa , como também Carmo (2003), avaliando o crescimento de três linhagens de tilápia em sistema semi-intensivo, obteve sobrevivência de $85,67 \%$, para a tilápia do Nilo linhagem comum, 94,33\% para a tilápia do Nilo linhagem chitralada e $92,67 \%$ para a tilápia vermelha, estando de acordo com os resultados obtidos neste trabalho.

A linhagem resultante do cruzamento entre as duas linhagens, neste trabalho denominada de mestiço, apresentou um desempenho satisfatório não diferindo do resultado apresentado pela linhagem chitralada, diferindo significativamente na maioria dos parâmetros da linhagem comum, indicando que características da linhagem chitralada predominaram sobre as características da linhagem comum.

A linhagem Chitralada como também o mestiço tiveram melhor performance que a linhagem comum, apresentando índices zootécnicos satisfatórios, sendo adequadas ao sistema de criação em tanques-rede.

\section{Referências}

BARBOSA, A. C. A.; ALMEIDA, L. D. V.; MEDEIROS, P. A. A.; FONSECA, B.R. Cultivo de tilápia nilótica em gaiolas flutuantes barragem do Assu - RN. In: INTERNATIONAL SYMPOSIUM ON TILAPIA AQUACULTURE, 5, 2000, Rio de Janeiro. Proceedings... Rio de Janeiro: Panorama da Aquicultura, 2000. v. 2, p. 400-406.

BARD, J,: KIMPE, P.; LEMASSON, J.; LESSENT, P. Manual de piscicultura para a América e África Tropicais. Trad. Antonio M. dos Santos \& F.V. Cruz. Nogent-Sur-Marne: França, 1974. $328 \mathrm{p}$.

BOSCOLO, W.R.; HAYASHI, C.; SOARES, C. M. Desempenho de machos revertidos de tilápia do Nilo (Oreochromis niloticus, L.), linhagens tailandesa e comum nas fases inicial e de crescimento. In: ACUICULTURA VENEZUELA, 1999, Puerto La Cruz, Venezuela. Anais... Puerto La Cruz, Venezuela: ASA, 1999. p. 84-91.

CARMO, J. L. Avaliação do crescimento de três linhagens de tilápia Oreochromis sp., em sistema semi-intensivo, cultivadas em viveiros. 2003. 63 f. Dissertação (Mestrado em Recursos Pesqueiros e Aqüicultura) - Universidade Federal Rural de Pernambuco, Recife. 2003. 
CARVALHO-FILHO, J. Informe publicitário. Panorama da Aqüicultura, Rio de Janeiro, v. 10, n. 60, p. 24, 2000.

CORREIA, E. S.; CARMO, J. L.; FERRAZ, L. B.; FERREIRA, D. A.; JÚNIOR, R. F.; SANTOS, R. M. S. Crescimento de três linhagens de tilápia (Oreochromis sp.) em viveiro de cultivo intensivo. In: CONGRESSO BRASILEIRO DE ENGENHARIA DE PESCA, 13, 2003, Porto Seguro. Resumos... Porto Seguro: CONBEP, 2003. p. 241.

FITZSIMMONS, K. Tilapia: the most important aquaculture species on the $21^{\text {st }}$ century. In: INTERNATIONAL SYMPOSIUM ON TILAPIA AQUACULTURE, 5, 2000, Rio de Janeiro. Proceedings... Rio de Janeiro: Panorama da Aquicultura, 2000. v. 1, p. 3-10.

FRANÇA, J. M. B.: LIMA, F. C. C.; SANTANA, A. C.; SILVA, E. J.; CORREIA, E. S. Crescimento de três linhagens de tilápia (Oreochromis sp.) em tanques-rede. In: CONGRESSO BRASILEIRO DE ENGENHARIA DE PESCA,13, 2003, Porto Seguro. Resumos... Porto Seguro: CONBEP, 2003. p. 240.

FÜLBER, V. M.; MENDES, L. D.; BRACCINI, G. L.; BARRERO, M. L.; DIGMEYER, M.; RIBEIRO, R. P. Desempenho comparativo de três linhagens de tilápia do Nilo Oreochromis niloticus em diferentes densidades de estocagem. Scientiarum Animal Sciences, Maringá, v. 31, n. 2, p. 177-182, 2009.

GALLI, L. F.; TORLONI, C. E C. Criação de peixes. São Paulo: NOBEL, 1987.119 p.

GOMES, L. C.; ROUBACH, R.; ARAUJO-LIMA, C. A. R. M. O sal de cozinha no transporte de peixes. Panorama da Aquiicultura, Rio de Janeiro, v. 72, p. 50-51, 2002.

KUBITZA, F. Tilápia, tecnologia e planejamento na produção comercial. Jundiaí: Editora Acqua Supre Com. Suprim. Aqüicultura Ltda, 2000. 289 p.

KUBITZA, F. A evolução da tilapicultura no Brasil: produção e mercados. Panorama da Aqüicultura, Rio de Janeiro, v. 13, n. 76, p. 25-35, 2003.

KUBITZA, F. O status atual e as tendências da tilapicultura no Brasil. Panorama da Aqüicultura, Rio de Janeiro, v. 21, n. 124 ,p. 10-19, 2011.

LEONHARDT, J. H.; CAETANO FILHO, M.; FROSSARD, H.; MORENO, A. M.; LOGAR, M. A. Ganho em peso e crescimento em três linhagens de tilápia do Nilo, Oreochromis niloticus, em tanques-rede. In: SIMPÓSIO BRASILEIRO DE AQUICULTURA 12 , Goiânia, 2002. Anais... Goiânia: SIMBRAQ, 2002. p. 186.

LOVSHIN, L. L., Wordwide tilapia culture. In: WORKSHOP INTERNACIONAL DE AQUICULTURA, 1, São Paulo, 1997. Anais...São Paulo: WIA, 1997. p.14-55.
MAINARDES-PINTO, C. S. R.; VERANI, J. R.; SCORVO FILHO, J. D.; SILVA, A. L. Desempenho produtivo da tilápia vermelha da Flórida Oreochromis $u$. hornorum x $O$. mossambicus e da tilápia tailandesa $O$. niloticus em tanque - rede de pequeno volume, submetidas a diferentes densidades de estocagem. In: SIMPÓSIO BRASILEIRO DE AQUICULTURA, 12, 2002, Goiânia. Anais... Goiânia: SIMBRAQ, 2002. p. 175.

MASSAGO, H. Desempenho de alevinos de quatro linhagens da tilápia do Nilo (Oreochromis niloticus) e análise da variabilidade genética pelos marcadores RAPD. 2007. 40 f. Dissertação (Mestrado em Recursos Pesqueiros e Aqüicultura) - Universidade Estadual Paulista, Jaboticabal, 2007.

MENDES, P. P. Estatística aplicada a aqüicultura. Recife: Bagaço, 1999. 265 p.

RIVELLI, S. Ensayo de cultivo de tilapia em jaulas. 2001 .Disponível em <http.// aquatic.unizar,es/N3/art1507/jaulastilapia. $\mathrm{htm}-18 \mathrm{k}>$. Acesso em: 21 de agosto de 2002.

SUGANUMA, C. H., REVALDARES, E., OLIVEIRA, C., FORESTI, F. Low levels of genetic variability in breeder stocks of nile tilapia Oreochromis niloticus based on microsatellites .World Aquaculture, Salvador, 2003. Book of abstracts...Salvador: WAS, 2003, v.2. p.764.

TAVARES, L. H. S. Limnologia aplicada à aqüicultura. Jaboticabal: FUNEP, 1994, 70 p.

TEIXEIRA, A. L. C. M. Estudo da viabilidade técnica e econômica do cultivo de Tilápia do Nilo, Oreochromis Niloticus, linhagem Chitralada, em tanques-rede com duas densidades de estocagem. 2006. 59 f. Dissertação (Mestrado em Recursos Pesqueiros e Aqüicultura) - Universidade Federal Rural de Pernambuco, Recife. 2006.

ZIMMERMANN, S. Incubação artificial, técnica permite a produção de tilápias do Nilo geneticamente superiores. Panorama da Aqüicultura, Rio de Janeiro, v. 9 n. 54 p. 15-21, 2000a.

ZIMMERMANN, S. Observations on Nile Tilapia (Oreochromis niloticus) from chitralada strain growth in two culture systems and three water temperature. In: INTERNACIONAL SYMPOSIUM ON TILAPIA AQUACULTURE, 5, 2000, Rio de Janeiro. Proceedings... Rio de Janeiro: Panorama da Aqüicultura, 2000b. p. 323-327.

ZIMMERMANN, S. Um moderno instrumental genético no melhoramento e na rastreabilidade de tilápias nilóticas. Panorama da Aquicultura, Rio de Janeiro, v. 13, n. 76, p. 69, 2003. 